\title{
La identidad como potencia: Del fracaso metafísico de lo biológico a la resistencia política de la restitución
}

\author{
Mariana Córdoba ${ }^{1}$
}

Recibido: 27 de julio de 2018 / Aceptado: 11 de noviembre de 2019

Resumen. Se cuestiona que la restitución de hijos/as de desaparecidos/as durante la última dictadura argentina exalta una concepción biológica, conservadora de la identidad personal. Argumentaré que el problema de esta noción no radica en la apelación a lo biológico, sino en la adopción de dos supuestos metafísicos: una ontología de individuos sustanciales y un esencialismo actualista. Propondré una concepción de la identidad relacional y como potencia o locus de poder, que permitirá re-significar lo biológico de la identidad y apoyar el fenómeno de la restitución.

Palabras clave: Identidad personal; ADN; restitución identitaria en Argentina; individuos discretos; identidad relacional; identidad como potencia.

\section{[en] Identity as power: From the metaphysical failure of the biological to the political resistance of restitution}

\begin{abstract}
It has been criticised that the restitution of children of people who disappeared during the last Argentinian dictatorship highlights a conservative biological conception of personal identity. I will argue that the difficulties of this notion are due to two metaphysical assumptions: an ontology of substantial individuals and an actualist essentialism. I will propose a conception according to which identity is relational and represents potency or locus of power. This will offer a brand new way to understand the biological feature of identity and support restitution.

Keywords: Personal identity; DNA; identity restitution in Argentina; individuals; relational identity; identity as potency.

Sumario: 1. El problema de la identidad personal. Apropiación y restitución identitaria; 2. Críticas a una supuesta concepción genética de la identidad; 3. ¿Qué es exactamente aquello que se critica? Sobre el supuesto conservadurismo de "lo biológico"; 3.1. El compromiso con individuos sustanciales con propiedades esenciales; 3.2. El compromiso con el esencialismo actualista; 4. Identidad relacional e identidad como potencia; 4.1. Prescindiendo de los individuos sustanciales: el ADN como marca de identidad relacional; 4.2. La identidad como potencia; 5 . Conclusiones y perspectivas; 6 . Referencias bibliográficas.
\end{abstract}

Cómo citar: Córdoba, M. (2020): “La identidad como potencia: Del fracaso metafísico de lo biológico a la resistencia política de la restitución”, en Revista de Filosofía 45 (2), 203-225.

1 CONICET / Universidad de Buenos Aires, Argentina

mariana.cordoba.revah@gmail.com 


\section{El problema de la identidad personal. Apropiación y restitución identitaria}

El problema filosófico de la identidad personal presenta diversas dimensiones: una metafísica, cuya preocupación fundamental es la de determinar cuál es el fundamento de la identidad, en qué consiste su naturaleza, y otra epistémica, relativa a las posibilidades de conocer en qué se basa la identidad y ofrecer un criterio para establecerla, de modo que sea posible re-identificar a una misma persona a través y a pesar de los factores de desemejanza que introduce el paso del tiempo.

En el marco de este problema, se ha insistido en la cuestión de la persistencia o de la re-identificación, entendida como la búsqueda de las condiciones necesarias y suficientes para que un ser presente sea el mismo que un ser pasado o futuro (Olson 2016). Esto ha sido incansablemente discutido por la filosofía analítica del siglo $\mathrm{XX}$. Para poder afirmar que una persona es hoy la misma que ayer, que un adulto actual es el mismo que determinado niño del pasado, se ha establecido la necesidad de apelar a una continuidad ininterrumpida a través del tiempo. La discusión ha versado sobre aquello en lo cual descansa dicha continuidad. En el debate analítico, el psicologismo sostiene que la continuidad de la conciencia garantiza identidad, mientras que el enfoque fisiológico-somático sostiene que la identidad depende de la continuidad de nuestro organismo biológico (animalismo) o de nuestro cuerpo (criterio corporal) $^{2}$. Si bien ha habido intentos de combinar estos enfoques, se suele privilegiar un aspecto determinado de la persona, para proponerlo como criterio epistémico de re-identificación y/o erigirlo en fundamento metafísico de la identidad. Los argumentos y contraargumentos ofrecidos apelan frecuentemente a los célebres experimentos mentales de la filosofía analítica: experiencias imaginarias de teletransporte, trasplantes y fisión de cerebros, entre otras, lo cual suele conducir a casos indecidibles, situaciones contra-intuitivas o paradójicas (Ricoeur 1996) ${ }^{3}$.

La filosofía analítica del siglo XX, en la que abundan estas situaciones aporéticas como resultado de la discusión sobre la identidad, hace gala de querer paradójicamente- fundamentar nuestras intuiciones ordinarias. No resulta demasiado problemático, en nuestra vida cotidiana, determinar que una persona es hoy la misma que ayer. Y esto es sumamente intuitivo, aún en el caso de la disimilitud que el envejecimiento y el crecimiento generan.

Sin embargo, el problema de la identidad personal se impone en ciertos debates debido a situaciones que nada tienen de intuitivas u ordinarias, ni tampoco de extravagantes escenarios configurados por experimentos imaginarios. Durante la última dictadura cívico-militar en Argentina (1976-1983), de acuerdo con un plan sistemático de las Fuerzas Armadas, aproximadamente 500 niños/as, hijos de los detenidos-desaparecidos por razones políticas por la misma dictadura, fueron violentamente separados de sus familias de origen para ser apropiados por familias que los inscribieron como propios, o dados en adopción ilegalmente.

El 24 de marzo de 1976, las Fuerzas Armadas irrumpieron, una vez más, en el curso institucional de la Argentina, desalojando a un gobierno elegido democráticamente. El golpe militar pretendió legitimarse en la supuesta inacción gubernamental para

2 El animalismo entiende el organismo biológico como una unidad de órganos metabólicos y vitales del animal humano, mientras que el criterio corporal hace descansar la identidad en la continuidad espacio-temporal del cuerpo. En este trabajo no se hará referencia a las discusiones filosóficas en torno a la noción de cuerpo, pero en tanto me centraré en el animalismo, retomaré más adelante algunas discusiones sobre la noción de organismo. Sobre este debate, cfr. Noonan (2003), Perry (2008), Olson (2016), Córdoba (2017). 
controlar la conflictividad social y la actividad de organizaciones político-militares que, en verdad, en ese entonces se hallaban política y bélicamente en claro retroceso.

La irrupción de las Fuerzas Armadas tuvo una doble direccionalidad: por un lado, reorientó la distribución de la renta hacia los sectores concentrados de la economía - exportadores y financieros- $y$, por otro, pretendió disciplinar a todos los sectores de la sociedad que contrariaran este modelo. La nueva orientación se impuso mediante una política represiva inédita en el país, incluso en el continente, desplegando acciones amparadas por la clandestinidad: desaparición de miles de ciudadanos y desinformación sobre su destino; fusilamientos en fraguadas evasiones y resistencia a la autoridad (la llamada "ley de fuga"); allanamientos domiciliarios sin orden judicial ni identificación de los actuantes; instalación de destacamentos militares en establecimientos fabriles, oficinas públicas e incluso hospitales; multiplicación de detenciones arbitrarias; seguimientos, amenazas y forzamiento al exilio de miles de activistas, gremialistas, estudiantes, intelectuales y artistas; despidos masivos a todo sospechado de "subversivo"; intervención sobre la prensa, implantando "listas negras", censura implícita y explícita; legitimación de la tortura como método de obtención de información. Todo el territorio nacional se pobló con más de 700 Centros Clandestinos de Detención y Exterminio por donde pasaron miles de personas, la mayoría de ellas luego asesinadas en la tortura, enterradas como $\mathrm{NN}$ o arrojadas a las montañas, selvas, ríos y el mar. Las estimaciones de tales prácticas arrojan resultados escalofriantes: 30.000 desaparecidos, 500 niños apropiados, además de varios miles de exiliados y detenidos a disposición del Poder Ejecutivo.

Además de la tortura perpetrada contra detenidos y detenidas, se sistematizó la tortura sexual y todo tipo de vejámenes a las mujeres, muchas de ellas embarazadas. Los bebés nacidos en cautiverio, en maternidades clandestinas, fueron apropiados, al igual que otros niños que fueron secuestrados junto a sus madres. Sabina Regueiro sostiene que la apropiación constituyó una política específica que tradujo la ideología política de la dictadura y que se dirigió a las familias de los opositores políticos -"subversivos". La apropiación se fundamentó en la categoría de "abandono" en la lógica jurídica: El abandono "pasaba a formar parte de los mitos de origen de los niños" (Regueiro 2013, p. 185), quienes, cuando no eran directamente apropiados por familias de militares y de las Fuerzas de Seguridad, eran institucionalizados o dados en adopción ilegalmente. Se ha establecido, sobre la base de testimonios de los apropiadores, que uno de los objetivos del plan sistemático de apropiación era "salvar" a los hijos de la "herencia subversiva", de acuerdo con una retórica salvacionista -sobre esto volveré más adelante. El circuito de ilegalidad en que ingresaron los menores apropiados, institucionalizados o adoptados, se articuló con la represión clandestina. Cuando la democracia fue restablecida, algunos miembros de las Fuerzas Armadas fueron juzgados y hallados culpables de los crímenes de desaparición forzada, tortura, asesinato, ocultamiento de información respecto del destino de los cuerpos, así como del delito de apropiación - en tanto cometidos por el Estado, todos ellos crímenes de lesa humanidad y, por tanto, imprescriptibles.

Durante la dictadura, las búsquedas que las familias realizaban aisladamente no daban resultados, como se advierte en el testimonio de un familiar: "(...) todavía no me daba cuenta de que realmente a los chicos se los querían quedar. Yo pensaba que los devolvían. Siempre pensaba que a la nena yo no la encontraba porque no sabía buscar. (...) no sabía que existían otras personas buscando desaparecidos." (en Nosiglia 2007, p. 33). La organización Abuelas de Plaza de Mayo (APM), fue 
fundada en 1977 por las abuelas de los niños apropiados con el objetivo de encontrar a sus nietos y restituirlos a sus familias originales. La búsqueda de esta organización contribuyó a la posibilidad de la determinación científica de filiación en ausencia de los padres: su demanda de recuperar a sus nietos y exigir justicia resultó en el hallazgo, por parte de los científicos, de un método para identificarlos. Dada la desaparición de los padres, fue necesario modificar las formulaciones matemáticas de la probabilidad de inclusión de paternidad/maternidad y, en su lugar, buscar la probabilidad de inclusión de abuelidad o "índice de abuelidad" - la probabilidad, expresada en porcentaje, de que un conjunto de abuelos y abuelas sean los abuelos y abuelas biológicos de un individuo determinado ( $c f r$. Penchaszadeh 2012) ${ }^{4}$. Las tecnologías de identificación de personas han adquirido en la actualidad un grado de avance tal que garantiza una altísima confiabilidad en sus resultados. Hasta el momento, 129 nietos han sido encontrados 5 .

¿Cómo fueron vividas las restituciones por los propios protagonistas? En muchos testimonios, nietos recuperados afirman que el conocimiento respecto de su verdadera filiación se identificó con el hallazgo de la propia identidad. Por ejemplo, Humberto Colautti dijo "Abuelas me encontró (...) Gracias a ellas, sé ahora quién soy". En este sentido, expresa Victoria Grisonas: "Haber recuperado mi identidad es haberlos conocido a ellos y también haberme conocido un poco más a mí, y haber logrado llenar un poco ese vacío que quedó ante la falta de mis padres". Y Guillermo Pérez Roisinblit afirma: "Recuperé mi identidad en el año 2004. (...) La identidad es lo único que te hace ser vos, es tu bien más preciado" (abuelas.org.ar). Las abuelas también han testimoniado: "A los 10 años del horror para nuestra familia, se nos dice por medio de un Documento Nacional de Identidad, que Paula es la que es, la que siempre fue, la que no pudieron borrar de la historia sus captores" (Elsa Pavón, abuela de Paula, citado en Herrera y Tenembaum 2007, p. 66).

El caso de la apropiación de hijos e hijas de personas desaparecidas y su posterior restitución identitaria debido al trabajo de APM, pensado desde la perspectiva de la cuestión filosófica, desafía el planteamiento mismo del problema. Lejos de requerir una teoría filosófica para dar cuenta de obviedades (“¿cómo sé que soy la misma que durmió anoche en mi cama?"), hace de la identidad de los nietos apropiados un campo de significaciones conflictivas, que dan cuenta de una confrontación política. Lejos de abstrusos experimentos mentales ("¿sigo siendo yo si pierdo la memoria, o si mi cerebro es trasplantado a otro cuerpo?"), el caso de la apropiación permite, sin embargo, abordar el problema de la identidad personal tal como fue formulado en la tradición filosófica: ¿a qué podemos apelar para saber si quien fue apropiado es ahora otra persona de quien creía (a pesar de las dudas) ser, pero el mismo que en verdad es? Buscar un rasgo responsable de la identidad, en términos de Paul Ricoeur (1996), consiste en la demanda de algo estable que garantice la permanencia en el tiempo, de acuerdo con el problema de la re-identificación. Veamos, entonces,

4 La investigación fue realizada en Nueva York por el científico argentino Víctor Penchaszadeh, el hematólogo Fred Allen, entonces director del Blood Center de Nueva York, la genetista Mary-Claire King, de Berkeley, California y miembros de la Asociación Americana para el Avance de la Ciencia.

5 Muy recientemente, el día 9 de abril de 2019, Abuelas de Plaza de Mayo anunció que se encontró a la nieta 129, quien tiene 42 años, vive en España y se realizó voluntariamente la extracción de sangre para el test de ADN el 3 de abril. Esta persona se presume que nació en cautiverio, durante la detención clandestina de su madre -quien continúa desaparecida y había sido secuestrada estando embarazada de 8 meses (cfr. https://www.pagina12. com.ar/186268-abuelas-confirmo-la-noticia-con-enorme-felicidad). 
cómo se ha planteado el problema de la identidad en relación con la restitución de hijos de desaparecidos desde la perspectiva del debate analítico, así como las críticas que pueden esbozarse desde una perspectiva narrativo-constructivista que intenta justipreciar el rol del ADN en la constitución de la identidad.

\section{Críticas a una supuesta concepción genética de la identidad}

La restitución identitaria motivó debates sobre la cuestión de la identidad, rescatando a la genética de su "mala prensa" (Bergel 2012), tanto en el seno de los organismos de derechos humanos como en ámbitos científico-académicos ${ }^{6}$. La genética irrumpe en el debate y fundamentalmente en los juicios por apropiación, siendo responsable de alumbrar una "verdad" al aportar el dato prácticamente irrefutable de los resultados de los análisis ${ }^{7}$, permitiendo probar el crimen de apropiación.

Como consecuencia de la irrupción de la genética en un ámbito eminentemente político, se ha discutido que la restitución identitaria lograda debido a técnicas científicas de identificación conlleva una idea genetizante de la identidad de las personas (Córdoba y García Fernández 2016; Córdoba y Quintana 2017). Se ha cuestionado que lo que oficia como prueba de identificación de personas se "ontologiza" (Gatti 2012) y así el criterio epistémico se convierte en fundamento metafísico de la identidad (Córdoba y Lipko 2013).

Se ha argumentado que el ADN de un individuo y el conocimiento de su filiación biológica no resultan suficientes para determinar su identidad. También se ha alertado que la "cristalización" de la estrategia de APM pueda conducir a comprometerse con el reduccionismo y el determinismo genético (Córdoba y Lipko 2013). En términos generales, el determinismo biológico es la tesis que sostiene que todas nuestras características son producto exclusivo de procesos biológicos. Algunas investigaciones en genética y etología sostienen que la personalidad, los intereses, el carácter y las enfermedades de los seres humanos se deben a sus genes. Desde una perspectiva crítica, Richard Lewontin, Steven Rose y Leon Kamin identifican dicha posición con la idea de que los seres humanos "no somos libres porque nuestra vida está fuertemente determinada por un número relativamente pequeño de causas internas: los genes que determinan comportamientos específicos o la predisposición de esos comportamientos." (2003, p.352). También críticamente, Víctor Penchaszadeh caracteriza el reduccionismo genético como la concepción según la cual "los fenómenos de la salud y la vida pueden reducirse a la acción de los genes y que por lo tanto las variaciones humanas en salud y rasgos de conducta se deben principalmente a variaciones genéticas y no a la acción del medio ambiente (2012, p. 178). Entre los exponentes del reduccionismo genético se encuentra Mark Ridley, quien afirma que los estudios con gemelos criados por separado probaron que existe un alto grado de heredabilidad para la personalidad; en función de esto, argumenta que no debe despreciarse la posibilidad de que los progenitores

6 Y también más allá de ellos. Resulta interesante analizar el fenómeno de personas adoptadas legal o ilegalmente que buscan a sus padres biológicos ( $c f r$. Gesteira 2014), y el debate en torno al "derecho a la identidad" de personas nacidas por medio de técnicas de reproducción asistida (http://concebir.org.ar/red-familias/). El fenómeno de la restitución sentó las bases de cierta interpretación del derecho a la identidad en Argentina.

7 La eficacia en la determinación del parentesco vía análisis de ADN es del 99,99 \% (cfr. Abuelas de Plaza de Mayo 2009). 
establecieran el carácter de los hijos en el momento de la concepción y no mediante la crianza, durante la infancia (2003, p. 471). Sin embargo, Lewontin, Rose y Kamin apelan al conocimiento biológico para sostener que el reduccionismo genético no viene exigido por aquel y, en la misma línea, Penchaszadeh lo caracteriza como una distorsión del conocimiento genético contemporáneo.

Volviendo al fenómeno de la restitución, el desplazamiento desde la prueba o criterio hacia el status de fundamento de la identidad personal impulsa las críticas a la supuesta noción de identidad involucrada en aquel fenómeno; desplazamiento que excede por completo tanto lo que la genética puede afirmar teóricamente acerca de la identidad, como las demandas de justicia para las cuales la prueba genética es requerida. Gabriel Gatti argumenta que las desapariciones forzadas, así como el conjunto de prácticas represivas efectuadas por la dictadura argentina han constituido un estado de confusión permanente de los mecanismos de construcción de significado y de subjetividad dentro de los cuales vivimos. Esta catástrofe social afectó, precisamente, a la identidad, devastando las bases sociales constitutivas de la misma. Dicha catástrofe fue confrontada por la incesante búsqueda de los nietos apropiados por parte de APM, y por medio de una peculiar noción de la identidad, "la de la narrativa del sentido", que "se construye a partir de dos materiales, dos de los más duros: “(a) el lazo biológico, esto es, la base genética de la identidad; (b) la familia” (Gatti 2012, p. 359).

El autor afirma que la demanda de restitución configura una concepción de la identidad anclada en "viejos sustantivos" como familia, origen, verdad, genética, biología; sustantivos que tienen un "tinte" conservador. Y analiza las tensiones que se producen entre una estrategia de resistencia y cierto conservadurismo que, paradójicamente, está a la base de dicha estrategia. Si las desapariciones y apropiaciones crearon un vacío -en tanto el desaparecido no deja rastros, ni hay rasgos a los que apelar para re-identificar a los niños apropiados-, a ese vacío se responde de acuerdo con una reposición de sentido sobre la base de la roca firme de la identidad. En efecto, las personas restituidas señalan en distintos testimonios que haber encontrado la verdad sobre su filiación constituyó una reposición no solo de conocimiento, sino también de sentido respecto de un aspecto fundamental de sí mismos que les había sido arrancado. Por ejemplo, Horacio Pietragalla Corti expresa: "Siempre había tenido un sentimiento extraño que no podía explicar. Cuando mi prima de crianza, Vicky, me confirmó mi origen, empecé a entender". En la misma línea, Pablo Javier Gaona Miranda dijo: "Veía a otros nietos y me identificaba con ellos, era raro lo que sentía" (cfr. Infojus Noticias 2015).

La estrategia de APM consistió, entonces, en responder a los efectos devastadores de la dictadura con una noción de identidad construida a partir del lazo biológico. De acuerdo con Gatti, táctica y estrategia mutan en definición ontológica: se produce una -ilegítima- ontologización del nexo entre identidad y ADN, por medio de una demanda política de justicia y sus peculiares estrategia y táctica-legítimas. Si la identidad se reduce a la sangre, entonces, en palabras del autor, "ser es ADN, ser es biología (...) La identidad, clave de bóveda del relato de los organismos de derechos humanos, en particular, Abuelas de Plaza de Mayo, o es así o no es." (2014, p. 37). Al riesgo de oscurecer el carácter social relacional de la identidad se había referido Carla Villalta alertando sobre la posible biologización del vínculo social (Villalta 2002). En este sentido puede interpretarse el testimonio de Juan Cabandié: "Hubo personas que se creyeron impunes jugando conmigo y sacándome la identidad 
durante 25 años. (...) Encontré la verdad hace 2 meses, soy el número 77 de los hijos que apareció. Cuando el análisis de ADN confirmó que soy hijo de Alicia y Damián, ahora sí puedo decir, soy mis padres (...), les pertenezco y tengo la sangre de ellos. (...) El plan siniestro de la dictadura no pudo borrar el registro de la memoria que transitaba por mis venas y me fue acercando a la verdad que hoy tengo." (Discurso 24/3/2004).

Por su parte, Sabina Regueiro afirma que si el ADN es necesario para demostrar identidad, no es, sin embargo, suficiente. Ni siquiera resulta suficiente "en el contexto judicial en el que el vínculo genético es determinante para la restitución de la identidad y el cambio de nombre: este por sí solo no basta a la hora de condenar a quienes se apropiaron de los niños, ni para que ellos puedan construir otros vínculos de parentesco" (Regueiro 2010, p. 19). La búsqueda de APM, de acuerdo con la autora, no debe ser interpretada en clave de reducción a lo biológico, sino que la identificación genética debe ser comprendida como uno entre otros pasos necesarios para re-construir un vínculo. Regueiro sugerirá que puesto que sin las prácticas sociales no existe lo biológico, carece de sentido asociar identidad y genética. El parentesco se construye política, jurídica y científicamente, pero la construcción científica, en el caso de las pruebas de ADN, es solo la portación de un dato. Ahora bien, dicho dato no refiere ni repone aquello que hay de "natural" en la relación de parentesco, porque, aunque pueda trazarse alguna conexión entre lazos de parentesco y biología, lo biológico solo tiene sentido en tanto una construcción cultural se lo imprima. Regueiro pone así en cuestión la vieja dicotomía naturaleza-cultura, afirmando que no hay naturaleza sin cultura (2010).

Si bien el discurso de APM enfatizó desde sus comienzos la importancia de la sangre, las raíces y los genes, sin embargo, la institución se había anticipado a las críticas, señalando que la genética no agota la identidad de una persona (Abuelas de Plaza de Mayo 2009). Sin embargo, las críticas aciertan al destacar que cierta retórica reiterada en nuestros días "exalta" el rol de la genética y la herencia biológica. Esto se debe a la efectividad del discurso de APM en la interpelación a la sociedad argentina (una sociedad sin dudas "familista") y a la potencia político-jurídica de las pruebas de ADN. Este tandem efectivo entre discurso "familista" y rol forense de las técnicas de identificación, pone de relieve dos aspectos de la identidad personal: el de la relaciónfiliación y el de los genes, cuya apelación refuerza "científicamente" las originales referencias a la "sangre" en el discurso de APM. A raíz del tándem mencionado, la filiación -social, política, construida- se lee con la lente biologizadora de los genes lo natural, lo biológico, lo dado. Ambos aspectos de la identidad parecen sintetizarse en uno solo, produciéndose así una superposición, por medio de la cual, además, los genes reducen la relación-filiación. Que la filiación no es eminentemente biológica, sino un lazo social, construido (Lo Giúdice 2005, Mascó 2005) -una obviedad en el ámbito de las ciencias sociales- parece ser puesto en cuestión tanto por la apelación discursiva a la sangre, cuanto por la interpretación que se hace de las pruebas de ADN en clave de resolución del enigma de la identidad de los nietos.

En este sentido cabe entender las críticas: suponiendo el carácter constructivosocial de la filiación, no puede el aspecto genético-molecular de las personas ser fundamento de la identidad. En línea con el debate analítico, podría cuestionarse que una concepción genética desatiende lo específicamente humano: al postular que la identidad personal descansa en un rasgo biológico, no se distingue de la de los animales no humanos. 
Según Ricoeur (1983), la identidad - personal y comunitaria- no depende de una continuidad biológica ni psicológica, sino que presenta un carácter narrativo ${ }^{8}$. El autor afirma que el debate en la filosofía analítica olvida la distinción fundamental entre dos tipos de identidad: mismidad e ipseidad. La mismidad o identidad-idem refiere a lo permanente o inmutable a través del tiempo, mientras que la identidad-ipse, por su parte, tiene un vínculo necesario con la alteridad: la otredad le es constitutiva (1996, 1999). El ADN de una persona permite determinar quién es alguien en el sentido idem de la identidad, porque garantiza, precisamente, la continuidad ininterrumpida a través del tiempo de un organismo biológico. Pero el genoma de un individuo no da cuenta de quién es una persona, aunque pueda resultar criterio necesario y/o suficiente para determinar la identidad de un individuo biológico. Si no se apela a la dimensión ipse de la identidad, se esconde el quién en el qué, la identidad de las personas se piensa al modo de la identidad de las cosas.

Giorgio Agamben sostiene que el concepto de identidad personal se transformó en la segunda mitad del siglo XIX debido al desarrollo de las técnicas de policía. Los métodos de identificación, ideados para delincuentes, nativos de las colonias y prostitutas, se universalizan; la identidad deja de estar en función de la persona y el reconocimiento para vincularse con meros datos biológicos, los que no pueden tener ninguna relación con la persona. La identidad de la persona depende así de "algo que le pertenece de modo íntimo y exclusivo, pero con lo que no puede identificarse de manera alguna." (2011, p. 72). La identidad que puede construirse sobre la base de meros datos biológicos es “(...) una identidad sin persona.” (2011, p. 75).

Respecto de las reivindicaciones identitarias de las personas apropiadas, el ADN funciona como criterio idem de identidad. Permite dar cuenta de que los niños y bebés apropiados son los jóvenes o adultos que hoy no podríamos reconocer dada la disimilitud producida por el paso del tiempo. Pero los puros datos biológicos no dan cuenta de la identidad personal (de un quién), sino de la identidad de una cosa (de un qué).

Ahora bien, la exaltación de lo biológico en el caso de la restitución, ¿conduce al conservadurismo al que parece arrastrar toda referencia a lo biológico?, ¿encubre el quién en el qué?, ¿nos reduce a esa vida desnuda (Agamben 2011) tan íntima pero tan ajena a nosotros mismos?

\section{3. ¿Qué es exactamente aquello que se critica? Sobre el supuesto conservadurismo de "lo biológico"}

Las críticas a la noción genetizante de la identidad tensionan el fenómeno político de la restitución identitaria en relación con el ADN y la reducción biológica de la identidad. Es mi propósito ensayar una nueva noción de identidad que permita apreciar mejor el fenómeno de la restitución desde una perspectiva filosófica que potencie la perspectiva política en lugar de reñir con ella.

De acuerdo con las críticas, debido a la divulgación del discurso de APM, se opera una "vuelta a lo biológico" en la apelación a la genética en relación con la identidad

No me ocuparé de la concepción narrativista de Ricoeur, una importante alternativa al debate analítico. Para los fines de este trabajo, baste señalar que, según Ricoeur, la identidad es un quiasmo entre historia y ficción, un particular entrecruzamiento entre un relato ficcional y un relato histórico. 
personal, que resulta en un posicionamiento conservador. ¿Por qué? Gatti argumenta que la caracterización de la identidad que se sigue de la estrategia de restitución implica conservadurismo: se trata de una identidad dura y firme, inflexible, no cambiante, que no es la identidad inestable del presente. Es una identidad que se reconstruye en clave de fortaleza, pues pretende combatirse con ella la catástrofe de la apropiación y la desaparición. De acuerdo con el autor, la política de la identidad que se articula en torno a esta noción es una política conservadora: la política de conservar lo que es. La identidad anclada en la familia, en la sangre y en los genes es comprendida como aquello que no puede variar, como aquello "semper idem" (2012, p. 354).

Por otra parte, la adopción del reduccionismo genético -caracterizado en la sección anterior-, implica una concepción conservadora de lo humano (de la personalidad, el carácter, la salud, etc.). Esto es así porque al suponer que está en la biología la causa de todo fenómeno humano, desde los rasgos físicos de los cuerpos y los comportamientos individuales hasta los de colectivos humanos, no hay lugar para el cambio, para re-elaboraciones o transformaciones posibles. Quién es cada uno de nosotros estaría respondido en el momento de la concepción. Cada acción y experiencia personal está, de acuerdo con esta posición, dictada por los genes, restringida por los patrones de comportamiento heredados de nuestros ancestros biológicos. Si esto es así, entonces, no solo nuestras características físicas, sino también los comportamientos de poblaciones, como las guerras o los genocidios, hallarían su razón de ser, en última instancia, en nuestros genes (Córdoba y Lipko 2013). Por ello, no solo carecemos de libertad y de posibilidad de transformación en el nivel individual, sino que asimismo todo estado de cosas -de opresión, de desigualdad entre las personas- queda justificado. En ese sentido, el determinismo genético respecto de la identidad es una posición conservadora: justifica los modos en que los seres humanos nos encontramos y vuelve fútil todo intento de cuestionarlos o revertirlos. Por otra parte, se ha cuestionado que anclar la identidad en la biología, la familia y los lazos de sangre es conservador puesto que esas ideas caracterizaron el discurso autoritario de la dictadura.

Hacer depender la identidad de los genes también es conservador según Gabriel Giorgi, porque "Democracia implica contestar permanentemente los marcos de naturalización por los cuales un orden de cuerpos se estabiliza; en las luchas democráticas del presente, politizar es, antes que nada, desnaturalizar y desbiologizar" (Giorgi 2014, online, resaltado en el original). Gatti, por su parte, sostiene: “(...) pensado como la materialización de la verdadera identidad, lo que porta ese líquido rojo expulsa fuera de esos sustantivos (verdad, identidad...) a muchas situaciones sociales donde esos términos están en cuestión: transgénero, adopciones, maternidades y paternidades múltiples (...)" (Gatti 2014, p. 37, resaltado en el original). Se asume que toda apelación a lo biológico acarrea conservadurismo. Pero ¿es necesariamente conservadora la apelación a lo biológico? ¿No es, acaso, conservadora toda apelación a la identidad "a secas"?

Una noción de identidad configurada en torno a la estrategia de restitución que resulte definida por la biología presenta consecuencias indeseables. Pero el mentado conservadurismo no se debe necesariamente a la exaltación de aquello que hay de biológico en la identidad -si es que hay algo-, sino a la cuestión misma de la identidad. ¿Por qué? Las críticas se dirigen contra una noción de identidad respecto de la cual se asumen acríticamente ciertos supuestos metafísicos. En primer lugar, se 
erigen contra una noción de identidad que, se presupone, es la del individuo como sustancia individual en sentido aristotélico (que supone una ontología de individuos identificables por sus propiedades esenciales) (3.1). En segundo lugar, se asume un esencialismo actualista de acuerdo con el cual la identidad descansa en un rasgo actual (3.2).

Explicitar estos supuestos y despojarse de su peso metafísico permitirá elaborar una noción de identidad distinta de la cuestionada en estas estrategias. Argumentaré que la identidad es relacional y no la del individuo sustancial con sus propiedades esenciales. Y que en este sentido debe entenderse la irrupción del ADN (4.1). Y, en contra del esencialismo actualista, sostendré que la identidad no descansa en un rasgo actual, sino que debe ser interpretada como potencia o locus de poder (4.2).

La nueva perspectiva me permitirá argumentar que las críticas a la "ontologización" del ADN no deberían dirigirse contra la apelación a lo biológico. Si, en lugar de ello, se cuestionan los supuestos metafísicos sobre los que descansa la noción de identidad involucrada, el rol de lo biológico puede re-significarse.

\subsection{El compromiso con individuos sustanciales con propiedades esenciales}

En el caso de la apropiación -como en el debate metafísico-, el problema central es el de la persistencia. La pregunta por la identidad es la pregunta por la mismidad de un individuo, por aquello que permanece idéntico a sí mismo a pesar del cambio. Aquello que permanece garantiza la identidad del individuo o sustancia individual; en términos aristotélicos, es lo que puede asumir contrarios, en tanto todo cambio supone un sujeto en el que darse ${ }^{9}$. En el caso de la identidad personal, paralelamente, se trata de la continuidad a pesar de los rasgos cambiantes que dificultan reconocer a la misma persona transcurrido cierto tiempo.

La pregunta por la identidad personal, la búsqueda de continuidad (psicológica o física) que asegure permanencia, carece de sentido si no se asume que es un individuo (personal o biológico) aquel idéntico a sí mismo. Las concepciones analíticas suponen que somos individuos distinguibles de los otros, cuyo fundamento ontológico no requiere de ninguna otra entidad. De otro modo, no cabría buscar un rasgo distintivo, un conjunto de propiedades esenciales que garanticen identidad y distinguibilidad. Psicologismo y animalismo o criterio corporal buscan una continuidad bajo el modelo de una ontología de individuos autosubsistentes.

Si en el debate analítico el individuo es o bien una entidad esencialmente consciente o bien una entidad esencialmente biológica, el fenómeno de la restitución sobre la base de los resultados de los análisis de ADN exalta la concepción fisiológicosomática de la identidad, situando el criterio biológico en el centro del debate. La restitución retrotrae el problema del individuo político y del sujeto metafísico al plano del individuo biológico.

9 No constituye un propósito del presente trabajo analizar el problema filosófico de la sustancia, su formulación original en Aristóteles, ni las nociones escolástica o moderna de sustancia. Acudo a estas nociones únicamente en la medida en la cual considero que el debate sobre la identidad personal ha sido interpretado como el de la identidad a secas; y este problema se ha planteado, en general, en términos sustancialistas. Esto es sumamente llamativo, dado que, en relación con la cuestión de la identidad personal, se afirma que todo lo que se ha escrito posteriormente no constituye sino notas a pie de página de la propuesta de John Locke (1980 [1690]) (Noonan 2003). Pero Locke dedica todos sus esfuerzos a argumentar que la identidad de las personas no debe confundirse con la identidad de la sustancia, de la que no depende y la que no supone. La identidad personal no radica en la identidad sustancial, sino exclusivamente en la identidad de un flujo de conciencia. Es sugerente advertir hasta qué punto las derivas lockeanas se han alejado de aquel original esfuerzo. 
Ahora bien, ¿cómo se comprende esta ontología de individuos?, ¿qué es un individuo? En la tradición aristotélica, el individuo es sustancia primera, objeto de predicación que no se predica de nada más. La reflexión contemporánea gira en torno a la búsqueda de un principio de individualidad (French y Krause 2006) para responder los siguientes interrogantes metafísicos: "¿qué hace que un individuo sea el que es y distinto de todo otro?”, y “qqué determina su persistencia?” (cfr. Lombardi y Castganino 2008). Acerca de aquello que confiere individualidad al individuo, se pueden distinguir dos estrategias filosóficas. Una consiste en afirmar que existe una individualidad trascendental, un substratum que actúa como soporte de propiedades ${ }^{10}$. Siguiendo a Hume -para quien el supuesto del sustrato constituye un "abuso metafísico"-, algunos filósofos empiristas sostuvieron que el individuo, en lugar de ser un substratum en el que inhieren propiedades, es meramente un haz de propiedades. Según esta segunda estrategia, las propiedades tienen prioridad ontológica respecto de los individuos, y lo que garantiza la identidad del individuo es un subconjunto de propiedades esenciales, en general espacio-temporales, junto con un principio que asegura que ningún otro individuo posee dicho subconjunto. En cualquier caso, ya sea que se los caracterice como substratum+propiedades o como haz de propiedades, los individuos son, bajo esta matriz, entidades con una existencia ontológicamente independiente, separables, y poseen un principio de individualidad que fundamenta su autosubsistencia y su persistencia. Los individuos son unidades completas que responden a la categoría de cantidad: son o bien uno o bien muchos, y pueden ser contados. La preeminencia de la categoría ontológica de individuo se advierte tanto en la física clásica como en las estructuras del propio lenguaje (Strawson 1959 y Tughenthat 1982).

Es esta matriz ontológica, configurada a partir de las categorías de individuo y de propiedad, la que signa el debate sobre la identidad personal. Los interrogantes metafísicos que estructuran el problema, "¿qué es lo que hace que una persona sea esa que es y no otra?" y "¿qué garantiza su persistencia a través del tiempo?" buscan una respuesta en términos de la identidad del individuo. Por otra parte, el individuo biológico -resaltando lo biológico- se pone en el centro del debate sobre el fenómeno de la restitución. La misma matriz ontológica permite comprender la discusión filosófica y el debate político sobre la restitución.

Una discusión reciente sobre la identidad personal y el conocimiento biológico contemporáneo en filosofía de la biología -muy lejos del fenómeno de la restituciónpermite tomar distancia de la idea de individuo biológico sobre la base de la matriz ontológica referida. Los organismos biológicos, también debido a una suerte de "abuso metafísico", son concebidos bajo el modelo del individuo sustancial. John Dupré (2014a, 2014b) y Anne Sophie Meincke (2016) afirman que en el debate sobre la identidad (especialmente en el animalismo), y siempre que se hace depender la identidad del ADN, se asume que somos individuos aislados. Dupré argumenta que la noción de individuo es un preconcepto metafísico y no viene exigida por la ciencia, y que a pesar de su centralidad en filosofía, "no es tan obvia como suele parecer" (2014a, p. 12). Por otra parte, en este marco metafísico tradicional, el cambio es una amenaza para la identidad. Sin embargo, en sentido estricto, lo que el

10 Esto estaba presente en la idea de "sustancia en general" de Locke. Algunas discusiones en filosofía de la física rescatan la noción de haecceitas de Duns Scoto, según la cual cada individuo tiene su propia haecceitas, lo garantiza su individualidad. 
cambio amenaza es una particular idea de individuo sustancial: "El cambio presenta un problema familiar para la metafísica de la sustancia, el de determinar qué cambios son consistentes con la persistencia (...)" (2014a, p. 15).

La irrupción del ADN en el debate sobre identidad y restitución retrotrae la discusión hacia la cuestión del individuo biológico. Esto pone de relieve la matriz ontológica de individuos-sustancias con propiedades y la exaltación de lo biológico (en detrimento de otros rasgos de las personas). La materialidad del ADN, entonces, conduce a pensar la identidad de las personas bajo el modelo de la identidad de las cosas. Además, la apelación al ADN permitiría reforzar una nota fundamental de la noción de individualidad, la idea de individuo autosubsistente. El ADN irrumpe en carácter de prueba de dicha individualidad.

Respecto de la restitución, la idea de una identidad auténtica, verdadera, que si bien fue violada y fraguada, no pudo ser completamente borrada se articula en torno al ADN. La identidad real recuperada es la de un yo, un individuo, de cuya continuidad da cuenta el ADN, donde no pudo llegar la desaparición: "Los milicos quisieron apropiarse de los chicos, pero no pudieron apropiarse de los genes" (Nora Cortiñas, citado en Giorgi 2014). Los análisis de ADN prueban que el individuo apropiado y ahora restituido sigue siendo él, se subraya su continuidad a través del tiempo, pero también se rescata su singularidad, fundamentalmente, respecto de sus apropiadores: se vuelve al "yo" original, a pesar de la crianza fraguada. En este sentido, algunos testimonios de nietos apropiados subrayan la oposición entre la verdadera identidad y la mentira en la que fueron criados: "Hasta que no tenés tu identidad real, no sos libre. (...) nos han mentido toda la vida y crecimos en la mentira", manifestó Sebastián Casado Tasca ( $c f r$. Infojus Noticias). La biología mantiene la "pureza" del individuo al distinguirlo de los apropiadores. El ADN es garante de mismidad, de identidad metafísica, pero es también punto de anclaje y demostración de la distinción radical de quien fuera apropiado respecto de la "falsa" familia en la que fue criado.

Entonces, bajo el modelo del individuo-sustancia autosubsistente y sobre la base de una exaltación de lo biológico, el ADN funciona -en términos del debate metafísico-como propiedad esencial que garantiza mismidad, distinción de los otros y permanencia en el tiempo. El ADN es principio de individualidad si aceptamos que estamos frente a una ontología de individuos sustanciales. Ahora bien, ¿debemos comprometernos con este supuesto? En el caso de la restitución identitaria de los hijos de desaparecidos ¿se trata de la identidad/autenticidad de ciertos individuos qua individuos? ¿No se trata más bien de la filiación, de un aspecto relacional de la identidad? ¿No se trata más bien de una política de la identidad que combate la apropiación, una política represiva que se dirigió, por medio de los niños apropiados, a un grupo en tanto que grupo? Nada en la idea de identidad vinculada con el ADN fuerza a pensar a las personas como individuos sustanciales y autosubsistentes, como veremos más adelante.

\subsection{El compromiso con el esencialismo actualista}

En el debate sobre la identidad, además de adoptar el supuesto de que somos individuos sustanciales, se asume un esencialismo actualista. Aquello sobre lo cual descansa la identidad, lo que nos hacer ser quienes somos, los mismos a través del tiempo y distintos de los otros, es un rasgo particular: una propiedad esencial o 
conjunto de propiedades esenciales actuales. Nuevamente, ¿en qué matriz, sobre la base de qué compromisos filosóficos se inscribe esta idea?

Ya Aristóteles había postulado la distinción entre acto y potencia para dar cuenta del cambio. Y resulta esclarecedor anclar en dicha distinción el problema de la identidad personal ¿Cómo se entienden las nociones de acto y potencia en la tradición filosófica y cómo se asume esta distinción en el debate sobre la identidad?

El cambio es, según Aristóteles, el pasaje de un estado de potencia a un estado de acto. Pero el acto es anterior a la potencia, no en el orden del tiempo, sino en el sentido de que tiene prioridad ontológica respecto de ella. El acto es comprendido como la realidad del ser, de modo tal que solo es posible comprender lo potencial a partir de lo actual. El acto es principio del ser, en tanto es lo que determina el ser, es decir, hace ser a lo que es (cfr. Moreau 1993; Barnes 1993). Esta afirmación es concordante con los modos en que se ha articulado la pregunta por la identidad de los individuos en el debate contemporáneo. En la búsqueda de la identidad se pretende encontrar aquello que hace que algo/alguien sea lo que es y no otra cosa/ persona. Siguiendo esta inspiración aristotélica, podría pensarse, entonces, que hay identidad porque hay acto. La propia pregunta por la identidad solo tiene sentido en tanto hay ser y, por lo tanto, en tanto hay acto. La potencia, en contraposición al acto, se muestra como el aspecto del cambio que amenaza el ser. Así, en la tradición filosófica, en tanto se asocia a la virtualidad, a la posibilidad, a una suerte de no-ser, la potencia es entendida como imperfección: un riesgo para el ser y la identidad.

En este marco tradicional, la identidad personal solo puede conjurar la amenaza del cambio si ciertas propiedades esenciales actuales acuden en su auxilio. La esencia sobre la cual la identidad descansa es siempre un rasgo actual. Todas las respuestas positivas que se han dado a la pregunta por la identidad ofrecen como criterio y/o fundamento, en cada caso, algún rasgo actual de las personas. Es la memoria, el cuerpo, los órganos del individuo discreto -que siendo él mismo cambia- lo que da cuenta de su permanencia o mismidad. Este es el marco ontológico en el que se dirime la cuestión de la identidad de las personas en el debate metafísico.

Por su parte, respecto del fenómeno de la restitución identitaria y del riesgo de asimilación entre identidad y genes o ADN, la discusión también se enmarca en la matriz de una idea de identidad personal arraigada en la tradición filosófica. En el caso de la restitución identitaria de hijos de desaparecidos, el ADN es la propiedad esencial actual que da cuenta de la mismidad del individuo, aquello que está a la base del cambio, lo que permite re-identificar a una persona. En este sentido, se afirma: "Los elementos sanguíneos sirven como base para los estudios de filiación porque (...) son expresiones de rasgos genéticos que, como los mismos genes, no se modifican con la edad, agentes ambientales, enfermedades ni por otros genes finalmente (...)" (Herrera y Tenembaum 2007, p. 190). El ADN, en tanto propiedad que el individuo posee actualmente a lo largo de toda su vida, resuelve el problema de la re-identificación de una persona como el niño robado en el pasado, probando además, de este modo, el delito de apropiación.

Recobra interés el debate metafísico sobre la naturaleza de los individuos, cuya individualización depende de propiedades actuales. Las propiedades potenciales, por su parte, se consideran deficientes, en tanto son aquello que aún no ha sido actualizado. Esta es la matriz en la que se inscribe la cuestión de la identidad/individualidad de las personas. De acuerdo con esta perspectiva ontológica, la posibilidad o potencia no es real, sino una suerte de carencia o falta de realidad, lo que pone en peligro al ser. 
El campo de la potencialidad, en sentido estricto, no es real como el de la actualidad. Pero esta no es la única manera de comprender la potencialidad.

\section{Identidad relacional e identidad como potencia}

Las críticas a la noción de identidad involucrada en la estrategia de restitución parten de la idea de que todo intento de vincular lo humano a lo biológico debe ser cuestionado. Porque si politizar un fenómeno es des-biologizarlo, entonces, rebiologizar un fenómeno es des-politizarlo. Y la lucha por la restitución en Argentina es una lucha política. Ahora bien, considero que no es la "vuelta a lo biológico" lo que debe ser interpretado como conservador, sino que resulta muy difícil escapar al conservadurismo de la identidad si esta es entendida como mismidad, como la identidad de una cosa, que descansa en un rasgo actual bajo el modelo de individuo sustancial. Lo conservador es el modo en que la filosofía tradicional piensa la identidad. Lo biológico, en este caso el ADN, encaja como la pieza final del rompecabezas de la identidad de la cosa/individuo biológico/persona.

¿Es posible apoyar filosóficamente la lucha política de APM como resistencia al fenómeno de la apropiación? Esta lucha ha fundado su estrategia sobre la noción de identidad basada en el ADN, con los peligros que ello implica. ¿Debemos, entonces, rechazar esta noción de identidad en el contexto del apoyo político a la restitución? ¿Debemos prescindir por completo de los resultados de la ciencia genética en este ámbito?

En apartados anteriores he identificado dos supuestos que han informado el problema filosófico de la identidad personal: el supuesto de individuos sustanciales y el esencialismo actualista. Si rechazamos tales supuestos, es posible defender una noción filosófica de identidad que no implique ningún tipo de conservadurismo, sino que ofrezca una nueva perspectiva para pensar la restitución. Esta propuesta -que permitirá sortear las críticas, pero mantener el aporte del ADN a la identidad personal- no supone el marco ontológico de los individuos sustanciales, sino que subraya el carácter eminentemente relacional de las personas (4.1.), y no presupone la prioridad ontológica del acto sobre la potencia, sino que se articula en torno del rol central de la potencialidad en la constitución de la identidad personal (4.2.).

\subsection{Prescindiendo de los individuos sustanciales: el ADN como marca de identidad relacional}

La identidad personal puede ser articulada rechazando el supuesto de una ontología de individuos sustanciales. Una noción de identidad vinculada con la noción de ADN y en relación con el fenómeno de la restitución no supone el compromiso con la idea de que somos individuos autosubsistentes, identificados por propiedades esenciales. Desde una perspectiva diferente es posible enfatizar el carácter relacional de las personas, permitiendo una rediscusión acerca de cómo comprender el lugar del $\mathrm{ADN}$, de los genes, de lo biológico en la identidad personal.

¿Hay algo en los resultados de los análisis, en el índice de abuelidad o incluso en el propio ADN que fuerce un modo particular de comprenderlo? ¿Estamos obligados a pensar que la identidad ligada al ADN es la del individuo sustancial, y que el ADN es la propiedad esencial que lo individualiza? En efecto, al igual que en el 
debate filosófico, cuando se hace depender la identidad del ADN, se piensa en la identidad del individuo (biológico). Sin embargo, ciertos argumentos provenientes de la filosofía de la biología sugieren que el conocimiento científico contemporáneo contradice la idea de que somos individuos biológicos sustanciales. De acuerdo con Dupré y Meincke, la biología contemporánea brinda más bien apoyo a la idea de que somos procesos biológicos y no individuos.

Dupré se pregunta en qué consiste ser un individuo biológico, y afirma que la noción de individuo es un presupuesto que la biología contemporánea no respalda. Porque "lo que encontramos en el mundo viviente son procesos profundamente interconectados e interdependientes, y distinguir individuos dentro de esos sistemas complejos es difícil, puede ser hecho de múltiples maneras, y puede ser contraintuitivo." (2014a, p. 12). De hecho, concebidos como procesos, los organismos biológicos que los humanos -también- somos, efectivamente somos en tanto estamos compuestos por subprocesos y en tanto formamos parte de procesos sociales, de colectivos mayores, de una variedad de entidades de nivel más alto. Es más adecuado y acorde a la biología contemporánea pensar el organismo humano como una entidad procesual más que como una cosa, como un proceso compuesto por "múltiples subprocesos biológicos y dependiente de su participación en múltiples procesos sociales." (Dupré 2014a, p. 14). Este autor argumenta que el $\mathrm{ADN}$, en tanto sistema complejo, constituye también un proceso. Por ello, propone abandonar la ontología de individuos, superar la perspectiva que nos piensa como individuos ontológicamente independientes, y asumir la idea de que hay una ontología procesual que conecta entre sí a los humanos (Dupré 2014b).

Meincke (2016) discute con el enfoque biológico de la identidad personal en el debate analítico y también sostiene que dicho enfoque se encuentra en desacuerdo con el conocimiento biológico contemporáneo. La razón de este desacuerdo es que las concepciones de la filosofía analítica descansan en una visión sustancialista de los organismos, que constituye una mistificación. El esquema ontológico en que se basa el animalismo en filosofía debe ser reemplazado por una ontología procesual. La noción de proceso ataca, precisamente, el núcleo del supuesto de la individualidad de los organismos, que parecía irrenunciable en el debate sobre la identidad. Si algo es esencial para que los procesos perduren, ese algo es el cambio (Dupré 2014a), paradójicamente, aquello que amenazaba la persistencia del individuo sustancial.

Por otro lado, en un contexto radicalmente distinto, Giorgi (2014) argumenta que, para el caso de la restitución, la noción de ADN debe ser re-interpretada. Frente a la paradoja de que la biologización potencie la politización de la restitución, "lo biológico" debe ser re-semantizado: “(...) la centralidad del bios en los derechos humanos (...) obliga a complicar las maneras en que pensamos lo biológico (...). $[\mathrm{P}]$ ensar esto implica asumir la vida biológica como la instancia no de significados predefinidos sino de una semántica abierta (...)". (Giorgi 2014, online, resaltado en el original). También Gatti re-significa su crítica, operando una re-interpretación del rol de lo biológico en determinadas reivindicaciones identitarias (Anstett y Gatti 2016). Esto no menoscaba las críticas, que son necesarias, sino que habilita a pensar que la posible sanguinización de los vínculos humanos no presenta una significación acabada de una vez y para siempre. Elisabeth Anstett y Gabriel Gatti afirman: “(...) los progresos de la biometría, la biología molecular, la lectura del Adn son una pieza esencial de las reivindicaciones ante el Estado de muchos ciudadanos, antes invisibilizados y hoy, en parte por los argumentos de los que provee todo esto, 
algo menos. Sin estas tecnologías serían imposibles políticas de derechos humanos sostenidas por la identificación vía Adn de los desaparecidos (...). Biopolítica de nuevo, pero invertida; sangre política pues, pero pensada ahora como la superficie de luchas que se sostienen en el "argumento biológico". Aquí, esos cachos de ciencia dura empoderan, y quienes son o fueron pensados, curados, reprimidos o civilizados por ellos se los apropian." (Anstett y Gatti, online 2016).

Siguiendo a Giorgi y a Anstett y Gatti, se puede sostener que lo biológico, en lugar de forzar una comprensión unívoca, aparece saturado de sentidos en el debate por la restitución; y, retomando los aportes de Dupré y Meincke, que nada en el conocimiento biológico contemporáneo obliga a pensar que la identidad biológica es la del individuo sustancial. Cabe preguntar, entonces, qué noción de identidad podría ensayarse para valorar de otro modo los resultados de los análisis de ADN en relación con la restitución identitaria. Es mi propósito ofrecer una reinterpretación que permita superar las críticas a la exaltación de lo biológico como elemento conservador.

Dado que no hay un significado cerrado que agote qué es "lo biológico", el individuo biológico no debe ser necesariamente interpretado según los supuestos metafísicos tradicionales. No parece haber razones suficientes para pensar que las personas humanas somos individuos autosubsistentes. Muy por el contrario, si algo enfatiza la referencia al ADN es la idea de la herencia como excedencia, como relación, como aquello que una generación pasa a la otra. En tanto materia que constituye un vínculo entre generaciones, su especificidad no es propia del individuo singular, no da cuenta de un individuo ontológicamente independiente. No es un rasgo positivo de un organismo, algo distintivo de un individuo (que permite distinguirlo de todo otro), sino más bien excedencia de un cuerpo compartido. En este sentido, la identidad ligada al ADN puede pensarse como imposibilidad de la autosubsistencia del individuo humano, en tanto materialidad que excede el cuerpo individual, en tanto marca de la relacionalidad imprescindible en toda persona. La identidad como aquello que la referencia al ADN permite probar y recuperar ya no es lo que viene reclamado por el individuo en tanto tal, sino lo que excede al individuo y pasa de generación en generación, materialmente. Por otra parte, los resultados de las pruebas de ADN interpretados de acuerdo con el índice de abuelidad permiten reponer la generación que falta, siendo testimonio y memoria material de la ausencia, de la generación intermedia desaparecida. Es una memoria material que "tiene su propio tiempo, (...) el de un entre-cuerpos, de eso que pasa entre los cuerpos y que aquí se compone alrededor de las familias (...). Esta memoria pasa por un tiempo que es menos el del cuerpo individual que el de las herencias (...)" (Giorgi 2014, online, resaltado en el original).

Desde esta perspectiva, si bien -en consonancia con el debate tradicional- se puede afirmar que el ADN permite re-identificar al individuo, no se trata del individuo como entidad autosubsistente, sino de una relación constitutiva del individuo. El ADN es prueba material de un vínculo, del vínculo biológico que se quiso borrar, pero también del ordenamiento familiar y social que se intentó desaparecer, fraguando relaciones familiares. Los resultados de los análisis de ADN constatan, eminentemente, la existencia de relaciones, de afectos, de ordenamientos familiares que persisten a modo de resistencia contra los órdenes fraguados.

Si los genes aparecen en el relato de Abuelas como aquello que resistió a la tortura y la desaparición, su presencia en el mundo de los vivos da cuenta de la paradójica 
presencia de los desaparecidos en sus hijos, en el sentido de una excedencia material que funda una comunidad (Córdoba y García Fernández 2016). Comunidad que nada tiene que ver con la idea conservadora de los lazos de sangre, ni es pensada como la suma de individuos discretos. Se trata de una comunidad cuya identidad permite recuperar a quienes no están y articularse como un poder, una potencia.

\subsection{La identidad como potencia}

Es la irresolución lo que sella el debate tradicional sobre la identidad. Los enfoques analíticos resultan esencialistas, parciales y reduccionistas (Córdoba 2015), y lejos de arrojar luz sobre la cuestión, conducen a aporías (Ricoeur 1996). Es mi convicción que el callejón sin salida de la identidad se debe a la adopción de una ontología de individuos sustanciales y a la exaltación de un rasgo actual como fundamento de la identidad.

Apartir de este marco analítico, pero tomando distancia de él, propongo comprender la identidad no dependiendo de un rasgo actual, sino como potencia, como locus de poder. Si la identidad es potencia ${ }^{11}$ y no acto, entonces se muestra como el territorio de disputa por excelencia en el que se puede dirimir la apropiación y la restitución. Si la identidad es potencia, entonces es posible intervenir las identidades, desafiando el planteo filosófico básico del problema: ya no se trata de buscar el rasgo estable que garantice permanencia, sino de reconocer un terreno de disputa donde diversas posibilidades se abren. Esta propuesta implicará un rebasamiento del problema tradicional en tanto toda identidad se mostrará esencialmente mudable, perdiendo así su peso metafísico la noción de fundamento como garantía de estabilidad.

Si las posiciones filosóficas tradicionales buscaron dar cuenta de la permanencia a pesar del cambio, la práctica represiva de la apropiación de niños dirigida contra su identidad evidencia, por el contrario, el carácter mudable de la identidad, revela que es posible intervenir las identidades. La identidad puede robarse, violarse, modificarse o torcerse, resultando un sujeto con una identidad impuesta, distinta de otra identidad previa. La práctica de apropiación de niños planificada por las FFAA tenía más de un propósito. Además de infligir daño a los padres y apropiar a los niños, dicho plan se proponía -sostiene APM-anular su identidad. El plan terrorista no se propuso la aniquilación de los niños, sino la sustitución de sus identidades, lo que se logró, en el ámbito jurídico, por medio de la falsificación de documentos y datos filiatorios. Como afirma Villalta, "Si en el contexto del Estado terrorista la persecución y el aniquilamiento fueron instrumentados a partir de la extensión de un mecanismo clasificatorio por el cual todos aquellos a quienes se quería eliminar fueron catalogados como 'subversivos' ( ...), con sus hijos esa lógica se combinó, en buena medida, con una actitud redencionista (...)" (Villalta 2012, p. 270, resaltado en el original). Puede afirmarse, entonces, que el propósito de las apropiaciones no se agotaba en modificar jurídicamente la identidad, era necesario asimismo rescatar a los niños, borrar su identidad heredada o potencial; si algún rastro de los padres quedaba en esos niños, debía ser reemplazado. El objetivo fundamental de un

11 No recojo aquí la noción de potencia en sentido aristotélico estrictamente. La potencia en Aristóteles es siempre potencia de algo determinado: un niño es potencialmente un hombre, pero un hombre no es potencialmente un caballo. El paso de lo que es en potencia a lo que es en acto exige estar en potencia de algo y no de otra cosa. Podríamos aventurar que, si bien la potencia no es un ser en sí mismo, parece haber incluso identidad de lo que es en potencia (no se es en potencia cualquier cosa, se es en potencia X y no Y). 
acto de apropiación se expresa como el de cambiar el signo de esa identidad ${ }^{12}$. En palabras de Villalta: "Esta sustracción estaba informada por específicos objetivos que, expresados en términos de evitar un hogar subversivo a esos niños, dan cuenta del sueño autoritario de producción de nuevos sujetos y relaciones sociales" (2010, pp. 200-201).

Por un lado, podría pensarse que los apropiadores creían estar ante una suerte de tabula rasa o punto cero identitario: al robar un bebé, se encontraban con un sujeto sobre el cual estaría todo por escribirse. Sin embargo, por otro lado, también consideraban necesaria la sustitución identitaria entendida como el aniquilamiento de una identidad previa. Porque presuponían que los niños provenientes de "familias subversivas" presentarían ciertas características heredadas. Entonces, subyacía la idea de que hay una herencia que debe ser arrasada, que hay una identidad latente, una tendencia que puede invertirse, re-educarse, anularse en tanto que posibilidad.

Por su parte, la estrategia de restitución ha mantenido siempre el propósito de que los niños secuestrados recuperasen a sus legítimas familias, asumiendo que existen identidades robadas que pueden ser restituidas. El trabajo de Abuelas fundó la posibilidad efectiva y simbólica de subsanar o revertir el fenómeno de la apropiación. Y si bien encontró en el ADN la marca de la permanencia que permite re-identificar a las personas apropiadas, también desafía la noción filosófica de identidad como anclada en un rasgo que permanece, al revelarse la identidad como algo dinámico.

Por esta razón, considero que la represión apropiadora y la resistencia de la restitución constituyen la ocasión de la puesta en cuestión radical de la identidad como estabilidad. La identidad personal se muestra así como un lugar de privilegio, un terreno disputado por victimarios y víctimas. El problema filosófico puede, pues, ser re-significado, pensando ya no la permanencia a través del tiempo, sino la identidad en el sentido de una potencia.

La identidad personal como potencia es un territorio de entrecruzamiento de sentidos, un terreno de disputa política. Constituye un locus de derrota o de victoria, de destrucción o permanencia, de represión o resistencia. Si, en sentido aristotélico, el acto es responsable de la perdurabilidad en tanto informa al cambio, siendo ontológicamente anterior a la potencia, la potencia es ella misma poder, es la posibilidad de producir algo distinto. Judith Butler $(2009,2010)$ entiende el reconocimiento -necesario y fundante de la persona y la identidad (Agamben 2011) - en términos de "sede del poder"; en este sentido, pienso que la identidad se revela como "sede del poder" ella misma. Esto nos permitirá sortear las paradojas del debate sobre las políticas de la identidad (cfr. Mattio 2009, Heyes 2016): lejos de defender posiciones identitarias fijas y anquilosadas, pero sin adherir tampoco a un esencialismo estratégico u operativo (Spivak 1990), esta propuesta permite pensar la identidad como potencia en términos de conflicto y transformaciones, como lo hace Kate Bornstein en ocasión de la discusión sobre identidad trans. La búsqueda de la identidad puede ser pensada en términos del deseo y el ejercicio de una transformación (Bornstein1994). Extrapolando esta idea al caso de la restitución, esta puede entenderse como una lucha por la transformación, no del individuo que

12 Eduardo Duhalde destaca, entre los propósitos con los cuales los niños eran robados, el de "educar a los niños menores, con una ideología contraria a la de sus padres.” (1983, p. 189). En este sentido, el represor Adolfo Scilingo declaró: “(...) a esos chicos había que rescatarlos y llevarlos a familias bien nacidas: a familiares de oficiales o amigos de oficiales, de la Armada o de otras fuerzas" (documental Botín de Guerra, David Blaustein 1998). 
restaura aquel signo original, auténtico de su identidad, que el acto de apropiación cambió primero, sino como una luch a política que hace de la identidad, poder: campo y arma de batalla. En tanto locus de poder, la identidad es el eje que articula cambio y permanencia de un modo diferente de como aparecen articulados en la tradición. Es, pues, en la dimensión de lo posible donde debe ser pensada la identidad: es maleable en tanto no puede ser en el modo de la definición/resolución.

Ahora bien, ¿cómo entender la dimensión de lo posible? Al afirmar que la identidad es potencia, entiendo el ámbito de lo posible en el sentido del posibilismo: los posibilistas sostienen, sobre la base de la distinción entre acto y potencia, que lo posible existe y es tan real como lo actual (cfr. Menzel 2018). Lo posible no es carencia, no es una suerte de no ser en el sentido tradicional, sino que es con pleno derecho. En nuestro caso, el hecho de que la identidad restituida como potencia es real, queda claro si atendemos a los efectos reales que produce. Fue la demanda de restitución la que dio origen al hallazgo del índice científico de abuelidad, así como a la creación del Banco Nacional de Datos Genéticos (Ley 23.511 13) y a la inclusión de los Artículos 7, 8 y 11 en la Convención Internacional por los Derechos del Niño ${ }^{14}$. La fuerza política y jurídica de las pruebas de ADN en relación con la identidad de los nietos restituidos ha producido -y seguirá produciendo- múltiples efectos reales: las condenas a los apropiadores en los juicios, un estado de cosas en el que existen familias legítimas e ilegítimas, la denominada "ley de ADN" (Ley 26.549 ${ }^{15}$ ), y cierta interpretación del derecho a la identidad.

Respecto de los efectos devastadores de la apropiación y de los efectos reparadores de la restitución, la identidad se revela como locus de poder. Si la apropiación es un crimen que se dirige contra la identidad de los niños, la restitución por medio de las tecnologías de identificación de personas, no solo permite dar la prueba, llevar a los represores a la cárcel y re-escribir una biografía personal, sino que también produce una identidad biológica, que encarna el poder de un re-encuentro familiar.

Si la identidad es poder, el hallazgo de cada nieto no constituye la resolución del enigma de la identidad individual, no define de una vez y para siempre una identidad recuperada, sino que es ocasión de conflicto y lucha política. La potencia, en contraposición a la noción de acto, es un no ser todavía, lo que pone en evidencia, precisamente, la latencia de toda lucha, de todo poder; es un locus donde aún se dirime una lucha. Si el acto hace ser a lo que es, la potencia, por el contrario, amenaza esa estabilidad, pero precisamente es la amenaza a la estabilidad el locus en el que son posibles las trasformaciones -en este caso, la reversión del fenómeno de la apropiación y todo lo que dicha reversión permite (y permitirá) crear.

\section{Conclusiones y perspectivas}

La concepción propuesta, de acuerdo con la cual la identidad es relacional y es potencia, permite justipreciar la relación entre identidad y ADN en torno al fenómeno de la restitución. Esta posición ofrece una respuesta metafísica al problema filosófico de la identidad personal. Pero es mi convicción que los problemas metafísicos adquieren

\footnotetext{
http://servicios.infoleg.gob.ar/infolegInternet/anexos/20000-24999/21782/norma.htm

http://servicios.infoleg.gob.ar/infolegInternet/anexos/0-4999/249/norma.htm

http://servicios.infoleg.gob.ar/infolegInternet/anexos/160000-164999/160779/norma.htm
} 
pleno sentido cuando son desafiados por problemas ético-políticos. Estos obligan a la reformulación de aquellos, que no son piezas de museo o cadáveres conceptuales, sino que exigen ser revisitados a causa del rebasamiento que les impone la realidad en que vivimos.

Con esta noción de identidad - que enfatiza la dimensión metafísica de la cuestión en su anclaje ético-político, en lugar de contraponer metafísica (ontologización y reificación del ADN como fundamento) versus política (estrategia de resistencia) pretendo acompañar las posiciones de Giorgi y de Anstett y Gatti a las que me he referido, así como todas aquellas posiciones que se encuentran realizando el trabajo político-conceptual de re-semantizar "lo biológico". Es esta una demanda instalada a raíz de la extraña e incómoda alianza entre genética, biomedicina y biología, por un lado, y derechos humanos, por otro, que tiene lugar en nuestro presente.

Respecto de cómo comprender lo biológico y la identidad, he traído al debate discusiones que, en el marco de la filosofía de la biología, pretenden desenmascarar supuestos metafísicos. Otras propuestas filosóficas que no se refieren al fenómeno de la restitución, sino que abordan la cuestión filosófica "pura" de la identidad, se han alejado de la matriz ontológica que he puesto en cuestión en este trabajo. Las propuestas -distintas entre sí y diferentes de la aquí defendida-de Guillermo Hurtado (2009) y Fernando Broncano (2013) pueden pensarse como compartiendo cierto aire de familia con la idea de identidad como potencia. Hurtado afirma que la persona es un modo contingente del ser humano. Y que, si esto es así, entonces la continuidad corporal es una condición necesaria pero no suficiente para su identidad en el tiempo (2009). Por esta razón, la pregunta de quiénes somos está siempre abierta: somos apertura ontológica que cualquier criterio de identidad (en términos de condiciones necesarias y suficientes) limita -y, por lo tanto, malinterpreta. Por su parte, Broncano cuestiona que el concepto moderno de identidad personal replica una indecisión entre dos formas de esencialismo: el mental y el corporal. Y, en armonía con las ideas aquí defendidas, afirma que "la identidad es una senda contingente, un devenir, no un estado o un objeto subyacente (hipokeimenon) (...).” (2013, p. 202).

El problema tradicional de la identidad puede, entonces, re-significarse y articularse, no como la búsqueda de la permanencia a través del tiempo, sino en el sentido de una potencia. En todo caso, la permanencia del "sí mismo" de cada nieto es política y es afectiva, es vincular, es histórica, y tiene que ver con la relación de filiación, con el deseo de otro, con contar para el deseo de otro, con una imposibilidad de ser borrado, en tanto exista otro que desee y busque.

¿Por qué no abandonar la noción de identidad? Ese tiempo aún no ha llegado, pues las tensiones que lo biológico revela, no sólo en el caso de la apropiación, sino también en otras reivindicaciones identitarias, continúan siendo un campo de batalla. Cabe, pues, buscar alternativas a la reificación de ciertos enfoques identitarios, pensando quizás en una ontología relacional. ¿Podremos pensar en una nueva ontología material, corporal (¿por qué no biológica?) colectiva; una nueva ontología que funda (no en el sentido del fundamento, sino de la inauguración) una identidad relacional, ligada a una materialidad que puede saltearse el hiato entre ausentes y presentes?

Finalmente, la alternativa propuesta para comprender la identidad para el caso de los nietos restituidos acompaña el fenómeno político sin caer iterativamente en esencialismos y paradojas y sin obturar lo biológico en una significación determinada. En tanto la referencia al ADN no es atadura conservadora, podemos comprender, 
bajo este modo de pensar la identidad personal, el fenómeno de los "desobedientes", el conjunto de hijos de ciertos represores que participaron del terrorismo de Estado en la dictadura argentina, agrupados por la "identificación como hijos biológicos de represores" 16 . No solo los reúne la desobediencia a los genes, la ruptura con su origen y el repudio de los crímenes cometidos por sus padres, sino también el compromiso político de querer declarar en la justicia contra sus padres, para lo cual demandan que sea modificado el Código Procesal Penal de la Nación que actualmente lo impide ${ }^{17}$. Vaya, entonces, si la potencia de la identidad no produce -y producirá- efectos reales en el mundo. Los desobedientes se reúnen en la rebeldía al mandato de la sangre, no a pesar de su ADN, sino precisamente en contra de él. El ADN es punto de anclaje de significados que exceden, y en la excedencia contradicen, lo "obligatorio": una marca imborrable, cuyo rastro habilita la coyuntura de una identidad como potencia colectiva en desobediencia, fundada en la indisciplina -nuevamente, como locus de poder.

\section{Referencias bibliográficas}

Abuelas de Plaza de Mayo (2009): Las Abuelas y la genética. El aporte de la ciencia en la búsqueda de los chicos desaparecidos, Buenos Aires, APM.

Agamben, G. (2011): "Identidad sin persona" en Desnudez, Buenos Aires, Adriana Hidalgo, pp. 67-78.

Anstett, E. y Gatti, G. (2016): “Sangres políticas”, Semanario Brecha, Montevideo Uruguay, diciembre.

Barnes, J. (1993): Aristóteles, Madrid, Cátedra.

Bergel, S. (2012): "El vínculo de la genética con los derechos humanos”, en V. Penchaszadeh (ed.), Genética y derechos humanos Encuentros y desencuentros, Buenos Aires, Paidós, pp. 41-67.

Bornstein, K. (1994): Gender Outlaw, Nueva York, Routledge.

Broncano, F. (2013): Sujetos en la niebla, Herder, Barcelona.

Butler, J. (2009): Dar cuenta de sí mismo. Violencia ética y responsabilidad, Buenos Aires, Amorrortu.

Butler, J. (2010): Marcos de Guerra. Las vidas lloradas, Buenos Aires, Paidós.

Córdoba, M. (2015): "Entre la esencia y la ausencia de la identidad personal. La obsesión por las determinaciones únicas". En C. Vanney y O. Lombardi (eds.), Fronteras del Determinismo Cientifico. Filosofia y Ciencias en Diálogo, Madrid, Editorial Biblioteca Nueva, pp. 201-212.

Córdoba, M. (2017): "Identidad personal”, en Diccionario Interdisciplinar Austral, editado por Claudia E. Vanney, Ignacio Silva y Juan F. Franck. URL=http://dia.austral.edu.ar/ Identidad_personal

Córdoba, M. y García Fernández, T. (2016): “¿Una concepción biologicista de la identidad? El derecho a la identidad: tensiones y profundidades teóricas." Trabajo presentado en $I X$ Seminario Internacional Políticas de la Memoria. Bs. As, Argentina, Noviembre.

16 En https://www.pagina12.com.ar/103813-con-la-verdad-antes-que-todo.

$17 C f r$. https://www.pagina12.com.ar/73921-contra-sus-padres. Sería muy interesante contraponer y pensar las relaciones posibles que, en torno de las significaciones asociadas a la herencia biológica, pueden trazarse entre nietos restituidos y desobedientes. 
Córdoba, M. y Lipko, P. (2013): "Identidad personal y genética: Reflexión sobre la cristalización de una estrategia”, Sophia,15, pp. 267-287.

Córdoba, M. y Quintana, M. (2017): "Personal identity and Science: The Genetic Approach Regarding the Case of the Children Appropriated During the Argentinean Dictatorship 1976-1983". Trabajo presentado en EPSA17. Exeter, UK, Septiembre.

Duhalde, E. L. (1983): El estado terrorista argentino, Buenos Aires, Argos Vergara.

Dupré, J. (2014a): "Animalism and the persistence of human organisms", The Southern Journal of Philosophy, 52, pp. 6-23.

Dupré, J. (2014b): “On genomics”. Philosophy Bites. Top philosophers interviewed on bitesized topics: John Dupré on Genomics. Disponible en: http://philosophybites.libsyn.com/ john-dupre-on-genomics

French, S., y Krause, D. (2006): Identity in physics: A historical, philosophical and formal analysis, Oxford, Oxford University Press.

Gatti, G. (2012): "Imposing Identity against Social Catastrophes. The Strategies of (Re) Generation of Meaning of the Abuelas de Plaza de Mayo", Bulletin of Latin American Research, 31 (3), pp. 352-365.

Gatti, G. (2014): "Las Abuelas, el gobierno de la sangre y la banalidad del bien", Semanario Brecha, Montevideo Uruguay, Septiembre.

Gesteira, S. (2014): "Más allá de la apropiación criminal de niños: el surgimiento de organizaciones de personas "adoptadas" que buscan su "identidad biológica" en Argentina", Runa 35(1), pp. 61-76.

Giorgi, G. (2014): "Genética marcada", en Informe escaleno. Octubre. En http://www. informeescaleno.com.ar/index.php?s=articulos\&id=269)

Herrera, M. y Tenembaum, E. (2007): Identidad, despojo y restitución, Buenos Aires, Abuelas de Plaza de Mayo.

Heyes, C. (2016): "Identity Politics", The Stanford Encyclopedia of Philosophy. URL = $<$ https://plato.stanford.edu/archives/sum2016/entries/identity-politics/>.

Hurtado, G. (2009): “Cómo convertirse en otra persona sin dejar de ser uno mismo" En Hurtado G., Por qué no soy falibilista y otros ensayos filosóficos, México, Los libros de Homero.

Infojus Noticias (2015) 31-08: http://www.infojusnoticias.gov.ar/nacionales/historias-denietos-restituidos-como-recuperaron-la-identidad-5355.html

Lewontin, R., Rose, S. Y Kamin, L. (2003): No está en los genes. Racismo, genética e ideología, Barcelona, Crítica.

Locke, J. (1980 [1690]): Ensayo sobre el entendimiento humano, Madrid, Editora Nacional.

Lo Giúdice, A. (2005): "Derecho a la identidad” en A. Lo Giúdice (comp.), Psicoanálisis. Restitución, Apropiación, Filiación, Buenos Aires, APM, pp. 29-42.

Lombardi, O. y Castagnino, M. (2008): “A modal-Hamiltonian interpretation of quantum mechanics", Studies in History and Philosophy of Modern Physics, 39, pp. 380-443.

Mascó, M. I. (2005): "La filiación como construcción” en Lo Giúdice (comp.). Psicoanálisis. Restitución, Apropiación, Filiación. Buenos Aires, APM, pp. 55-62.

Mattio. E. (2009): “¿Esencialismo estratégico? Un examen crítico de sus limitaciones políticas", Construyendo nuestra interculturalidad, 5 (4), pp. 1-11.

Meincke, A., "Biological identity and personal identity", Biological identity conference. School of advanced study, University of London. 02-06-2016 Disponible en: https:// www.youtube.com/watch?v=yl_A6kGVtXI\&t=1596s

Menzel, C. (2018): “Actualism”, Edward N. Zalta (ed.), The Stanford Encyclopedia of Philosophy (Summer 2018 Edition), URL $=<$ https://plato.stanford.edu/archives/ 
sum2018/entries/actualism/>.

Moreau, J. (1993): Aristóteles y su escuela, Buenos Aires, EUDEBA.

Noonan, H. (2003): Personal Identity, $2^{\circ}$ edición, London, Routledge.

Olson, E. (2016): "Personal Identity". En The Stanford Encyclopedia of Philosophy (Spring 2016 Edition), editado por Edward N. Zalta. URL = http://plato.stanford.edu/archives/ spr2016/entries/identity-personal/

Penchaszadeh, V. (2012): "Uso de la identificación genética en la reparación de la violación del derecho a la identidad durante la dictadura militar argentina", en V. Penchaszadeh (ed.). Genética y derechos humanos Encuentros y desencuentros, Buenos Aires, Paidós, pp. 263-298.

Perry, J. (ed.). (2008): Personal Identity, Segunda Edición, Berkeley, University of California Press.

Regueiro, S. (2010): “Análisis genético para la identificación de niños apropiados: construcción política y científica de la "naturaleza" y el parentesco". Revista Estudios Feministas, 18(1), pp. 288-299.

Regueiro, S. (2013). "El secuestro como abandono. Adopciones e institucionalizaciones de niños durante la última dictadura militar argentina”. Katálysis 16(2), pp. 175-185.

Ricoeur, P. (1983): Temps et récit. 3 volúmenes, Paris, Du Seuil.

Ricoeur, P. (1996): Sí mismo como otro, Madrid, Siglo XXI.

Ricoeur, P. (1999): "La identidad narrativa". En Historia y naratividad, Barcelona, Pensamiento contemporáneo 56, pp. 215-230.

Ridley, M. (2003). Evolution. Oxford, Blackwell.

Strawson, P. (1959): Individuals. An Essay in Descriptive Metaphysics, London, Methuen.

Tugendhat, E. (1982): Traditional and Analytical Philosophy: Lectures on the Philosophy of Language, Cambridge, Cambridge University Press.

Villalta, C. (2002): "Entre el derecho a la identidad, el propio cuerpo y las pruebas genéticas" Argentina: CFA/Universidad de Buenos Aires. Manuscrito no publicado. Citado en Regueiro (2010).

Villalta, C. (2010). "Uno de los escenarios de la tragedia: el campo de la minoridad y la apropiación criminal de niños”. En Villalta, Carla (comp.) Infancia, justicia y derechos humanos. Buenos Aires, UNQ Editorial, pp. 199-242.

Villalta, C. (2012). Entregas y secuestros. El rol del Estado en la apropiación de niños. Buenos Aires, Editores del Puerto/CELS.

Spivak, G. (1990): The Post-Colonial Critic: Interviews, Strategies, Dialogues, Sara Harasym (ed.), New York, Routledge. 